This is an Accepted Manuscript of an article published by Taylor \& Francis in Development in Practice on 20/05/2008, available online:

http://www.tandfonline.com/doi/pdf/10.1080/09614520802030433

Published as:

Jones, Nicola, Bekele Tefera and Tassew Woldehanna (2008) "Childhood poverty and evidence-based policy engagement in Ethiopia", Development in Practice 18 (3): 371-384.

The article is reproduced in accordance with the self-archiving policies of Taylor\& Francis. 


\title{
Childhood poverty and evidence-based policy engagement in Ethiopia
}

\author{
Nicola Jones with Bekele Tefera and Tassew Woldehanna
}

\author{
Authors \\ Nicola Jones, Overseas Development Institute \\ n.jones@odi.org.uk (contact author) \\ Nicola Jones is a research fellow at the Overseas Development Institute interested in \\ questions about the knowledge/policy/practice interface. Previously she worked as the \\ Policy Research Manager for Young Lives in the Policy and Communications \\ Department at Save the Children, UK. \\ Bekele Tefera, Save the Children UK, Addis Ababa. \\ yl-scethiopia@ethionet.et \\ Bekele Tefera is the National Coordinator for Young Lives Ethiopia. He has worked for \\ many years in Save the Children UK on issues of childhood poverty, health and \\ nutrition.

\section{Tassew Woldehanna, Dept of Economics, Addis Ababa University tassew.woldehanna@wur.nl Tassew Woldehanna is an Assistant Professor of Economics at Addis Ababa University. His research interests include agricultural development, micro-credit and childhood poverty. He is the Principle Investigator for Young Lives Ethiopia.}

\begin{abstract}
This paper explores efforts to bridge multi-disciplinary research and policy engagement to tackle childhood poverty in developing country contexts, based on the experiences of Young Lives, an international longitudinal policy research project. It focuses on a case study involving the utilisation of research evidence on childhood poverty to shape policy debates about Ethiopia's second generation Poverty Reduction Strategy Paper (2006-10). The discussion is situated within theoretical literature on the knowledge/policy/practice interface which supports the reconceptualisation of policy making as a non-linear dynamic process. It pays particular attention to the importance of understanding the political and policy contexts of Southern countries rather than simply importing Northern-derived models of advocacy. It concludes by teasing out generalisable lessons for translating research into social policy change.
\end{abstract}




\section{Introduction}

This paper explores efforts to bridge multi-disciplinary research, policy engagement and practice to improve the life quality of children living in poverty in a developing country context. Despite comprising up to $50 \%$ of the population in low-income countries (UNICEF, 2005:12), children are often marginalised within development and poverty alleviation debates. Drawing on the experiences of Young Lives, an international longitudinal research project on childhood poverty (2000-15), our case study focuses on the utilisation of research evidence about the child poverty-related impacts of the first Ethiopian Poverty Reduction Strategy Paper (PRSP 2002-5) to strengthen the poverty analysis and policy prescriptions of the second generation PRSP (2006-10). The discussion is situated within theoretical literature on the knowledge/policy/practice interface which supports the reconceptualisation of policy making as a non-linear dynamic process involving multiple actor networks with varying interests and informed by competing policy narratives (local and global). This focus is particularly important in under-researched polities at different stages of democratisation, decentralisation, and economic development where Northern-derived models of advocacy are unlikely to be appropriate.

The paper is organised as follows: Part 1 presents the theoretical framework which is then used to analyse the Ethiopian case in Part 2. Part 3 concludes by reflecting on the strengths and weaknesses of our strategy. It attempts to tease out some generalisable lessons-both ingredients for success as well as potential stumbling blocks-for translating research into social policy change.

\section{The challenge of non-linear, dynamic policy processes}

In the world of development policy - where policy making has historically been viewed as a simple linear progression from technical evidence, to policy design, to accurate implementation- the failure of poverty reduction policies has been interpreted as a problem of inadequate and/or poor quality evidence-based policy making. Premised on the belief that better research tools would lead to superior policies and outcomes, the 1990s/2000s saw the creation of multiple poverty assessment initiatives, as well as an array of international development and poverty reduction targets (McGee and Brock, 2001:4). In order to monitor and potentially hold national and international policy makers accountable to their official commitments to poverty amelioration, researchers and activists recognised the importance of quantifiable indicators and related data collection. Similarly, in the case of children's issues, in order to measure progress in realising the United Nations Convention on the Rights of the Child and the child-related Millennium Development Goals (MDGs), specialised quantitative surveys focusing on children and their caregivers were initiated; for example, UNICEF's Multi Indicator Cluster Surveys and DFID's Young Lives (YL).

The penchant for quantifiable poverty assessment approaches is understandable in that they help to address important information gaps concerning the patterning, distribution and identity of those living in poverty. Nevertheless, quantitative surveys are likely to be of limited value in shaping social policy if they are not contextualised within the complexities of the policy process itself. Lucinda Platt (2003: 2) in her survey of the interaction between research on child poverty and related social policies in the UK between 1800 and 1950, aptly notes:

"The impacts of research may occur neither at the time of the research, nor in ways that are predictable....[Impacts are] mediated by the options available to 
policy makers at a particular time. [There is a] ...need for research to be both radical and relate to its time and place... Its influence will vary with the political complexion of the country and ideological and religious factors. It is both to make an impact but also to accord, at least in part, with existing mores."

\section{Non-linear dynamic policy processes}

In trying to account for the complexities of policy formulation and implementation, a newly emerging body of policy processes literature underscores the importance of reconceptualising policy making as a non-linear, dynamic process. Theorists such as Keeley and Scoones (2003: 27-8) argue for a 'structuration approach' which combines the insights of three different schools of thought as to what drives policy change: a) political interests derived from actors' structured interests, b) actor agency stemming from an on-going process of inter-actor negotiation and bargaining, and c) discursive practices, reflecting a Foucauldian understanding of the inter-relationship between power, knowledge and policy.

This approach attempts a middle ground between policy as a linear process and policy as chaotic and accidental. It recognises structural constraints and the difficulties inherent in negotiating the complex and messy dynamics of the policy process, but nevertheless leaves room for agency and change:

"Policy approaches are likely to be influenced by dominant policy discourses and narratives, by powerful combinations of political interests and by effective actornetworks... but this should not lead to the conclusion that policy processes inevitably end in impasses. Each discourse, actor-network or policy network involves institutional practices and interactions that are made up of the activities of individuals. At these multiple interfaces there may be "policy spaces" or "room for manoeuvre" to promote alternative approaches to policy" (ibid.: 29). Of importance here is the recognition of policy influencing as an iterative process with multiple but comparatively narrow opportunities to affect change. Policy is shaped significantly by interpretation and practice, and by policy actors from multiple sectors (line ministries and departments) and levels of government decision making (i.e., central, regional, local) that are involved in implementation.

\section{Different modes of engagement}

If we understand the policy environment as an arena with multiple, shifting but relatively narrow access points, two basic types of interaction are open to those pursuing policy engagement and dissemination strategies. The first can be characterised as 'argumentative interaction': a more critical or combative approach involving strategies to 'build alternative actor networks [and ...] dislodge dominant positions and their associated networks' (Keeley and Scoones: 2003: 30).

However, while there is clearly a place for challenging existing paradigms that underlie inappropriate policy decisions, proponents of 'participatory' or 'deliberative democracy' (eg, Dryzek, 1994) contend that political change is often more effective and enduring if proponents attempt to foster more participatory forms of governance and decision making. This second 'communicative interaction' approach seeks to build participatory, consultative partnerships involving research networks, community groups and NGOs, and national and local government stakeholders, in which a diversity of values, perspectives and goals is negotiated and reflected (Keeley and Scoones, 2003: 31). The extent to which these policy engagement strategies are available to proponents of change will largely depend on the specific political and social climate of a given country. 


\section{Young Lives practice - an Ethiopian case study}

With a broad emphasis on civil society engagement and learning from international experiences of the first generation of Poverty Reduction Strategies, the development of Ethiopia's second PRSP (2006-10) presented an important opportunity for YL to combine its research, advocacy and dissemination strategies. An 18-month programme of multi-disciplinary research on the impact of the first PRSP (the Sustainable Development and Poverty Reduction Paper) on childhood poverty and policy engagement was mapped out including:

- quantitative analysis of YL' 2002 household survey with 3,000 families - new qualitative data collection and analysis in five of YL's 20 sentinel sites to better understand the underlying dynamics between policy change and household-level and child-level outcomes

- an analysis of national and sub-national policy frameworks and implementation practices, as well as

- a multi-pronged dissemination and communications strategy involving seminars with key stakeholders, the development of documentary video and photography projects, and capacity building workshops with national and state-level policy practitioners.

The research was structured around key MDG-related themes (a key organising framework of the first PRSP). The themes were: i) the child-, household- and community-level determinants of children's nutritional status; ii) school enrolment and achievement outcomes; and iii) involvement in labour activities (both paid and unpaid). In each case we were interested in exploring inequalities among children based on gender, poverty status, urban/rural location and regional state residency. In order to contextualise these sector-specific analyses, we also carried out a child-sensitive critique of the first SDPRP document, comparing the Ethiopian PRSP document with that of ten other countries' PRSPs, encompassing a range of development levels, political systems and continents (2).

\section{Ingredients for successful research-based policy influencing}

The art of effective research-based policy influencing is still only partially understood, but a growing body of research on the linkages between research and policy has identified a number of key ingredients including: a) the importance of credible quality research, b) an intent to shape policy, c) understanding and factoring in the sociopolitical context in which the research will be taken up, d) identifying and networking with key governmental, civil society and international organisation actors, and e) the importance of context-appropriate packaging of messages (e.g., Court et al., 2005).

The following discussion uses these five criteria to evaluate YL Ethiopia's efforts to mainstream children into PRSP policy dialogues as well as the final document. It concludes with reflections on eventual outcomes - both successes and failures.

a) Quality evidence Analysts interested in exploring how best to bridge policy and research are at pains to emphasise that quality evidence is essential (eg, O’Neil, 2005). But how should we best define this? YL sought to ensure quality across three broad dimensions: the research sample, the integration of quantitative and qualitative methods, and analysis from a multi-disciplinary perspective. First, the YL Ethiopia sample is not only relatively large (3,000 households) but spans five of the most populated regions of the country (approximately 90 per cent). Although not nationally representative, it reflects a diversity 
of agro-ecological zones, livelihood patterns, cultural and religious traditions, human development levels and ethnic compositions. It also provides valuable information about the impact of macro-level poverty eradication/development policies in diverse subnational contexts.

Second, we purposefully combined quantitative and qualitative methodologies in order to complement breadth with depth (e.g. White, 2002). The quantitative analysis (using multi-variate regressions) allowed us to aggregate our findings about the determinants of various aspects of childhood poverty (nutritional and educational deprivations, exposure to paid and unpaid work). The qualitative analysis, meanwhile, allowed us to develop a richer understanding of childhood poverty. It provided greater insight into causal processes and the complex dynamics behind quantitative findings that initially appeared counter-intuitive. Moreover, by working with a team of researchers to carry out more than 250 mixed community dialogues, focus group discussions and semi-structured interviews with key informants, caregivers and children, we went some way towards meeting what Moser (2003) has termed the need for 'apt illustration' (as compared to anecdotal evidence) through quantifiable qualitative research.

"[There is a need to shift] goalposts as to the definition of robustness so that it becomes more "inclusive" of quantifiable qualitative research. Only this can ensure that social issues do not remain confined to anecdotal boxes, but provide information of equal comparability in poverty assessments" (ibid: 82).

Lastly, the research team combined multiple academic disciplines: economics, political science, public health, sociology and gender studies. Although doubtlessly more timeand labour-intensive than mono-disciplinary research, the combined perspectives enabled our work to resonate with diverse audiences. Econometric analysis provided us with currency in the language of power: not only are economists highly respected in Ethiopian society but we were largely trying to persuade economist-trained officials in the Ministry of Finance and Economics as well as the donor community. Simultaneously, contextual sociological analysis and in-depth case studies allowed us to translate technical econometrics analysis into a more compelling human-centred narrative about the implications of the PRSP on child well-being. As Court and Maxwell (2005: 719) have argued, a key ingredient of policy engagement necessitates highly developed storytelling skills - 'the storytelling expertise of Sheherazade'.

b) Intent matters Although research may have an impact on policy practitioners' thinking and practice through the process of 'knowledge creep' - whereby ideas gradually filter through to a broader array of policy stakeholders (Weiss, 1980) - there is a growing consensus that research explicitly designed to influence policy will have a better chance of success than research that relies upon chance or accident to shape policy change. As O’Neil (2005: 762) argues: 
"This might seem like a rather fragile proposition, that practical influence on policy depends to a large degree on the state of mind of researchers, but the hard evidence of many cases support the claim that intent matters. It matters precisely because the confusions, tensions and accidents of the policy process itself turn out to be so complicated and unpredictable. ... Research will only have a reliable influence on policy if it can survive if research is designed from the start and carried out and translated to the policy people with a resolute and explicit and specific intent."

YL—a partnership between a research consortium and an international INGO-was created with a strong emphasis on research utilization and making research accessible to Southern policy makers and communities. In the Ethiopian case, a team comprising academics from Addis Ababa University housed under the government's Ethiopian Development Research Institute (EDRI) and development practitioners from Save the Children UK explicitly designed research on the impacts of the first PRSP to feed into debates on the development of the second PRSP or Plan to Accelerate Sustainable Development and Eradicate Poverty (PASDEP 2006-10). In this regard timing was very important: we had to provide ourselves sufficient lead time to carry out and write up a body of research to meet the government's drafting deadlines, and hold stakeholder workshops on our findings with donors, government officials and civil society groups. Clearly, the completion of working papers after these deadlines would have been of little practical value.

c) Context In order to engage effectively with policy practitioners, it is important to understand how policy decisions are made, which groups or coalitions are politically powerful and which issues are politically sensitive and why (eg, Court et al, 2005). We need to consider for example: whether the policy process is consultative and seeks to represent the viewpoints of a broad range of stakeholders, or is determined by a small group of government officials largely behind closed doors; the relative balance of power between political institutions and what the best entry points are for policy influence and dialogue (3); as well as the contours of the interface between civil society and policy decision makers: is the relationship constructive, complementary or antagonistic?

Prior mapping of the Ethiopian policy and advocacy environment had indicated that the policy process was dynamic and non-linear but divergent from developed country contexts on a number of levels:

- the balance of power between political institutions was firmly tilted towards the bureaucracy;

- civil society umbrella groupings and the media were still fledgling and suffered from significant capacity constraints (both internal and in their legal capacity to openly challenge government priorities and policies); and

- NGO engagement with the PRSP process was relatively superficial and restricted. The real negotiations would be between the donor community (which wielded considerable power through significant aid flows) MOFED and key sector ministries.

In terms of children and representation of their needs, we also realised there was a dearth of understanding of children's rights issues among government and civil society organisations, especially in terms of how broader macro development and poverty reduction policies might impinge directly and indirectly on their lives. In light of this environment, it was clear that policy influencing should target MOFED and donors, but 
simultaneously seek to build capacity among legislators, regional governments (where policy decisions are implemented), and mainstream civil society groups so that they would also come to endorse efforts to design more child-sensitive policies.

What we were less prepared for, however, was the speed with which the political context would shift. Although we were aware that national-level elections would take place a few months before the PASDEP process was scheduled to be finalised, few analysts were able to predict beforehand the contentious nature of the election process. Unexpectedly high turnout and a surprisingly strong showing by the new coalition of opposition forces in May 2005 had two major implications: a) discussions about (including media coverage of) the PRSP were overshadowed by highly charged debates about the election, election fraud and violent unrest in Addis Ababa and b) the credibility of the main civil society umbrella group, the Christian Relief and Development Association (CRDA), was called into question in the eyes of the government due to its alleged link to the opposition. This resulted in the demise of an already fragile (but previously thawing) relationship between civil society and the ruling party/government. As a result, the ability of YL to portray its evidence as non-political and research-based, combined with the project's long-standing affiliation with the governmental EDRI, constituted essential elements in being able to secure a platform to launch our findings and policy recommendations.

This suggests that in societies in flux, policy research endeavours need to carve out a cooperative but separate identity from mainstream policy networks and epistemic communities (4). Such a strategy does, however, pose dilemmas for advocates, particularly those from Northern-based institutions. On the one hand there is the pressure to locate oneself and operate in the way that will most effectively raise issues of concern. On the other, there is considerable pressure to work in solidarity with local civil society. But while the latter is valuable in terms of process, the YL experience suggests that, rather than adhere rigidly to only working through civil society groups, there is a need to take a more flexible, situation-specific approach in order to ensure social-change oriented outcomes.

d) Networking and identifying key players Accumulated learning by researchers and activists has shown that a sense of government and community 'ownership' of a research project is likely to facilitate the acceptance and recognition of the research findings. Following Keeley and Scoones' (2003) communicative interaction approach to policy influencing, one of the central aims of YL has been to promote government and community buy-in from the outset. In the Ethiopian case this has been implemented by housing the research component of the project within EDRI (which is headed by the Prime Minister's Chief Economics Advisor); securing approval from the Disaster Prevention and Preparedness Committee for the dissemination and advocacy components carried out by Save the Children, as well as the formation of a project advisory panel (comprising key sector ministry officials and donor and international organisation representatives).(5) In addition, at seminars with donors and government officials, where we launched our research findings, we invited key players in the PRSP development process to give presentations on how they were seeking to incorporate children's rights, the United Nations Convention on the Rights of the Child (UNCRC) and the MDGs into the second PRSP. In this regard, rather than seeking only to criticise existing government policies, or to embarrass prominent officials into action, we instead provided space for officials to reflect on the relationship between broad poverty development strategies and children's rights, and to develop an argument as to how they were trying to strengthen these linkages. 
Building on insights about the Ethiopian policy process and advocacy environment outlined above, we also paid particular attention to ensuring that we had formal and informal discussions with key figures in the PRSP drafting process. In this regard we were in a fortunate position as one of the YL researchers was involved in an advisory capacity to the PRSP committee. In other words, they were serving as a 'policy entrepreneur' (Kingdon, 1984), that is, an actor in or close to government who is willing to make an investment in moulding issue-specific policy strategy development. Although we did not gain access to information that was not publicly available in some form, this link helped us to prioritise where to focus our research and advocacy energies, to better understand what type of information was needed and how decisions would be made. Armed with this knowledge, informal discussions with the head of the PRSP technical committee were held over the course of the research process, facilitated by the fact that this person was also simultaneously a member of the YL Ethiopia advisory panel. This in turn enabled us to identify key individuals within the powerful planning departments of each of the main sector ministries, who represented their ministry's perspective in the PRSP committee. It also provided us with an opportunity to directly disseminate our research findings and related policy recommendations.

We also sought to network with civil society groups seeking to influence the PRSP process, but closer networking with MOFED suggested that government officials were wary of civil society umbrella groups. This was not only because the respective roles of the CRDA and PANE had not been clearly communicated to the PRSP committee, but also because there were questions about the rigour of their analysis and evidence base. This experience further highlighted that partnership projects like YL need to be flexible about who delivers its policy messages. As Court et al. (2005) argue, the messenger matters in facilitating the translation of ideas into policy action. Whereas some persons/ institutions are viewed as appropriate sources of particular types of research, research seen to be outside their organisational mandate may be rejected. Perhaps not surprisingly, NGOs and donors tend to value NGO studies, while government officials and international financial institutions express greater confidence in research that they themselves commissioned or endorsed.

e) Framing research messages One of the key differences between research that is confined to library shelves and research that leads to policy change is the way the findings are packaged. We need to consider: i) the use of culturally and audience-appropriate discourses, ii) the construction of pithy narratives that do not unnecessarily 'dumb down' what are often complex messages, as well as iii) the development of specific concrete policy recommendations.

In the first case, insights from social movement theory are illuminating. Collective action does not result from a simple conversion of objective socio-economic conditions into demands for change, but rather depends on subjective perceptions of injustice and the way in which political discourses are framed in culturally resonant ways (e.g. Tarrow, 1995).

"Movements frame their collective action around cultural symbols that are selectively chosen from a cultural tool chest and creatively converted into collective action frames by political entrepreneurs" (ibid: 119).

In this regard, research projects seeking to influence policy change need to be aware of what types of arguments are culturally palatable. For example: do international conventions command respect or ignite anti-colonial/imperialist tendencies? Are social 
welfare measures viewed as a sign of progress or do they provoke negative memories of a state socialist past? In the Ethiopian case, while international conventions and standards hold some sway, due to the powerful position occupied by donors, there is simultaneously a culture which is weary about accepting international norms without first assessing their feasibility in a development context that confronts multiple challenges (eg, low-income country, multi-ethnic society, recent history of political turmoil, etc). Therefore the current emphasis is on ensuring that international frameworks are 'localised' - for example, rather than speak of the UNCRC, officials prefer to look towards the national version, the 'National Action Plan for Ethiopian Children'. In this vein, it is essential for Northern organisations to partner with Southern institutions who are more attuned to cultural sensitivities.

A second dimension of appropriate framing relates to the way in which research findings will be remembered. King et al (2005) argue that skilful narratives and pithy summaries are needed to encapsulate the key elements of the research conclusions. Given the public, and in particular the media's, penchant for messages in sound-bite format, there is a frequent danger that the impact of findings will be diluted or even misinterpreted if they are stripped from their context.

The overarching message that YL Ethiopia sought to communicate was that children are not only impacted by education and health sector policies - broader development and poverty reduction policies can have a profound (and perhaps greater) impact on their well-being, and thus children's rights need to be mainstreamed into national policy frameworks. By adapting the language of gender mainstreaming - which has been widely adopted throughout development circles - we sought to convey the message that not only do all sectoral ministries need to consider the direct or indirect impact of their policies on children, but that policy makers must pay attention to the potential synergies or contradictions among policies on child outcomes. In particular we wanted to highlight contradictions or inconsistencies with general development policies on the one hand and child-specific policies on the other, which are often unintended and go unnoticed by policy advisors and analysts. Policies designed to increase aggregate household income (such as credit generation schemes for women to purchase livestock) for example may have an unintended negative impact on children if they result in less caring time for children or in the involvement of children in animal herding: that is, if alternative policy measures (eg, community childcare mechanisms and communal grazing policies) are not simultaneously adopted.

Lastly, as Saxena (2005) argues, researchers seeking to change policy need to be proactive about teasing out the policy implications of their findings, rather than leaving such interpretation to policy makers who may distort conclusions to better meet their own political interests. If researchers do not do this, there is also the risk that 'In the process of an idea being turned into action, it may turn from a silk purse into a sow's ear' (ibid: 749). In the case of the Ethiopian PRSP process, our connections with the PRSP technical committee and donors had underscored the need to translate our findings into specific quantifiable progress indicators that could be measured using existing data sources. In other words, if we wanted the PASDEP to be more child-sensitive than its predecessor, what indicators would we recommend be included in the list of indicators against which Ethiopia's progress and hence aid flows would be evaluated? Boiling down complex mixed-method, multi-level analyses on children's nutrition, education and labour status to concrete indicators is, of course, a daunting task. Accordingly, once our findings were clear, we carried out content analyses of ten other PRSPs which had been identified as comparatively child-sensitive (Marcus $e$ t al, 2002) to identify possible 
indicators that could be adapted to suit the Ethiopian context. We then summarised these findings in a three-page policy brief, which we distributed widely to the government and donor PRSP committees.

In addition to indicators, the Ethiopian Development Assistance Group (DAG) emphasised the importance of ensuring that the research-based policy recommendations that we developed were not stated in general terms (eg, 'mechanisms to support women's triple work burden - productive, reproductive, community - are needed to improve child well-being') but rather were linked to specific existing policy frameworks. They urged us to develop policy conclusions that would suggest revisions to particular policy programmes: for example, 'the August 2004 New Safety Net programme's recommendation to introduce community-based childcare mechanisms needs to be adequately funded and implemented in all regions in order to ensure that children's nutritional status does not suffer when poor women involved in income-generating activities outside the home are compelled to leave their children unattended'.

\section{Evaluating Outcomes}

It is undoubtedly difficult to evaluate the impact of a particular research project on policy given the complexities of the policy process discussed above. We also recognise that shaping the content of a policy document such as the PRSP does not guarantee a reduction in childhood poverty outcomes but rather we would argue that it provides credibility and an important leveraging tool for future policy influencing initiatives, particularly at the sub-national level. Given these constraints we outline below a) changes in behaviour and attitudes of key actors in the PRSP process to which we can trace YL's contribution and b) changes in the child-related content of the PASDEP when compared to Ethiopia's first PRSP that are in keeping with YL research-informed policy recommendations.

Over the course of our 18-month long policy influencing strategy, strong relationships with the following governmental and civil society actors contributed to a number of significant actions that we would argue in turn shaped the final PASDEP content:

- Engagement in informal dialogues on childhood poverty as an issue to be addressed in the PRSP with senior PRSP technical committee members, as well as planning officials in key sectoral ministries (esp Education and Capacity Building, Health, Agriculture and Rural Development)

- Active participation on the part of the PRSP technical committee in national and sub-national YL seminars and dissemination events, including presentations on how the Ethiopian government is tackling childhood poverty issues

- Persistent follow up by the PRSP technical committee with individual sectoral ministries to submit child-related materials to ensure cross-governmental ownership

- Willingness by the Department of Child and Youth Affairs (previously located in the Ministry of Social Affairs and Labour and now in the Ministry of Women's Affairs) to work in partnership with YL to translate the core principles of the Action Plan for Ethiopian Children into their poverty analysis and indicator matrix submitted to the PRSP technical committee

- Requests by regional state governments (Tigray and Amhara) for copies of all YL research outputs in order to prepare their Five Year Strategic Plans, suggesting at a minimum an awareness of the importance of attention to children's rights. 
- Adoption of some of YL's key points on childhood poverty (especially a rights discourse and the need to address the effects of paid and unpaid child work on children's education and development) in the shadow document prepared by Ethiopia's main poverty-focused civil society umbrella group, the Poverty Action Network Ethiopia (PANE). [6] (This was seen as a critical achievement as the NGO shadow report to the first PRSP made scant reference to children, and prominent civil society leaders were initially sceptical about the linkages between macro-development policies and micro-impacts for children).

\section{Impact on final document}

Perhaps most importantly, YL was invited by the PRSP technical committee to submit text identifying the key points identified in our research as critical for tackling childhood poverty along with measurable indicators. A sizeable chunk of this text was subsequently incorporated into the final PASDEP document (see Section 7.13 "Addressing the Particular Needs of Children" (7)). In particular, our research and related policy messages emphasised throughout our policy influencing work the importance of recognising childhood poverty as analytically distinct from household poverty and the need to conceptualise childhood poverty as a deprivation of rights. Both of these key arguments were incorporated for the first time in the PASDEP, including a recognition of the need to tackle childhood poverty because of risks of life-course and inter-generational transmissions of poverty as well as commitment to revise related legislation to protect children's rights and to implement and monitor progress in achieving the National Plan of Action for Ethiopian Children (NPAEC) (see Section 7.14.3 "Justice System Reform Program"). In addition, a simple document analysis methodology (see Table 1) highlights not only the higher frequency of references to children but also a broader range of childrelated issues reflected in the PASDEP compared to the first Ethiopian PRSP (8).

\section{INSERT TABLE 1 HERE}

There were some disappointments, however. Although one of the three strands of our work was on child work and implications for child schooling, no specific reference to child work or child labour is found within the PASDEP. (There is only an indirect reference through the emphasis on integrating the NPAEC). Similarly, while our own research as well as best practice from other PRSPs emphasised that a lack of protection from abuse may be an integral part of a child's experience of poverty and suggested a number of related indicators to measure progress, although mentioned in the narrative none of the progress indicators we recommended were included. This lack of a more comprehensive discussion of the multi-dimensionality of children's experiences of poverty was particularly disappointing given that considerable space was devoted to an extensive discussion on gender and poverty reduction. It suggests that advocates of child well-being have important lessons to learn from colleagues involved in gender equality initiatives, especially their relative success over time in securing more detailed and international buy-in.

\section{Conclusions}

Young Lives (YL) Ethiopia's efforts to use research findings to advocate for a more child-sensitive second PRSP support findings of existing literature on research-policy linkages and also expand our collective understanding about effective research-based advocacy in developing country contexts. 
1. Research needs to be credible. Due to what Ahmed (2005: 767) dubs the 'multiplier effect', if research includes inter-disciplinary perspectives and mixed methodologies it is likely to prove more persuasive than mono-disciplinary work. In seeking to persuade the key drafters of the Ethiopian second PRSP about the importance of incorporating children's rights into the document, econometric analysis was powerful, while in-depth qualitative research enabled us to understand our findings in human terms and to make sense of sometimes seemingly counter-intuitive quantitative results.

2. The intent to shape policy change is significant given the complexities of the policy process. Policy makers' demands for research findings to be translated into specific, context-appropriate indicators and policy recommendations meant that if shaping the second PRSP had not been our conscious aim, it is unlikely we would have taken the necessary steps to undertake this interpretative task. The effort required to package an academic-style research paper into readily accessible policy-relevant messages is considerable and cannot be left to chance.

3. The politico-institutional context matters. Our experience highlighted two dimensions in particular. First, it is critical to engage with officials with meaningful budget-related decision-making power. For example, advocates of childhood poverty need to dialogue with ministries of finance and economics and not only typically weaker social affairs ministries. Second, in an at best fledgling democratic environment, where governmentcivil society relations are still fragile, initiatives to shape policy need to be mindful of these tensions. The YL Ethiopia experience suggests that a dual strategy of engagement may be most conducive to ensuring social change. This would balance independent dialogue with officials in order to fulfil a neutral knowledge translation function, alongside networking and awareness-raising with civil society coalitions in order to develop a broader support base.

4. The importance of securing strong relationships with key players or policy entrepreneurs cannot be underestimated. Such linkages provide vital information on officials' information needs, decision-making hierarchies, processes and timelines. In addition, YL' experience suggests that research findings are unlikely to be accorded the necessary credibility if stakeholder buy-in to a project's objectives are not previously established. In some political contexts this may include housing part of a research project within a government-affiliated agency as was the case with our linkages to the Ethiopian Development Research Institute. In other words, the credibility of the messenger needs to be taken as seriously as the development of messages themselves.

5. Framing of messages in succinct, easily remembered and culturally-resonant ways provides a linguistic bridge between often complex academic texts and policy action. This packaging needs to take into account politico-cultural and ideological sensitivities, and for this Southern partners' insights are essential. Reference to international best practices can strengthen policy recommendations but only if care is taken to ensure that ideas are adapted to the local context.

The YL Ethiopia experience also offers some fresh insights about the timing of policy engagement; the value of long-term partnerships between NGOs and researchers; securing stakeholder buy-in; and investing in capacity building so as to forge broader supportive alliances. 
1. It is imperative to add a temporal dimension to understanding the political and institutional context in which advocacy is to be carried out. Mapping exercises are necessary, but often tend to be quite static. Instead they should also identify areas that are fluid and fragile, as well as key political junctures at which the balance of power and institutional arrangements could be vulnerable to significant change. This could include elections (as was the case in Ethiopia), outcomes at major international events (eg, G8, MDG summit in 2005), the disintegration of actor coalitions, or even the emergence of conflict situations. Advocacy and dissemination strategies need to factor in the possibility of such abrupt shifts in the political context and need to be sufficiently flexible to cope with a new environment.

2. While analysts of policy and research linkages have recognised the value of alliances between researchers and advocacy organisations, too little emphasis has been placed on the sustainability of these relationships. The YL model suggests that investment by donors such as DFID in fostering long-term alliances between researchers and NGOs-which can play a knowledge brokering or translation role, especially vis-à-vis non-traditional audiences-is valuable. It provides a credible platform from which research-informed policy influencing initiatives can be launched over time, rather than having to build up legitimacy from the ground up in each new research endeavour.

3. Although there is increasing recognition that it is important to foster stakeholder buy-in to research projects in order to ensure 'ownership' from the design stage through to subsequent usage of the results, more could be done to involve stakeholders more actively. Inviting policy decision makers to present their thinking in public fora alongside the launching of one's own research findings contributes to breaking down the sense of 'stakeholders as targets' and instead promotes a model of 'stakeholders as partners'. It also provides decision-makers with an opportunity to engage actively with issues that they perhaps lack familiarity.

4. Capacity building can play a potentially important role in shaping the politicoinstitutional context. If a mapping exercise reveals, for instance, that parliamentarians are relatively weak political players and that the media and civil society have limited capacity to offer important checks and balances on the power of the government, a longer-term strategy to influence policy could consider investing in capacity building with these groups. If social change is contingent on addressing power imbalances within the policy process then contributing to the capacity development of less powerful actors (both governmental and civil society) may be a more sustainable policy influencing strategy. 


\section{References}

Ahmed, M. (2005) 'Bridging research and policy development', Journal of International Development 17(6):765-73

Court, J., I. Hovland and J. Young (eds) (2005) Bridging Research and Policy in Development: Evidence and the Change Process. London: Overseas Development Institute.

Crewe, E., I. Hovland and J. Young (2005) 'Context, evidence, links: a conceptual framework for understanding research-policy processes', in Court et al. (eds) (2005)

Dryzek, J. (1994) Discursive Democracy: Politics, Policy and Political Science, Cambridge: Cambridge University Press

Keeley, J. and I. Scoones (2003) 'Understanding Environmental Policy Processes: A Review', IDS Working Paper Series, No. 89, Sussex: Institute of Development Studies

King, K., Palmer, R. and Hayman, R. (2005) 'Bridging research and policy on education, training and their enabling environments', Journal of International Development, 17(6):803-17

Kingdon, J. W. (1984) Agendas, Alternatives, and Public Policies, New York: Harper Collins.

Lockwood, M. "Will a Marshall Plan for Africa make poverty history?" in Journal of International Development 17(6):775-789.

Marcus, R, J. Wilkinson and J. Marshall (2002) 'Poverty Reduction Strategy Papers (PRSP) - What can they deliver for children in poverty?' The Journal of International Development 14(8):1117-1128

McGee, R. and Brock, K. (2001) 'From Poverty Assessment to Policy Change: Processes, Actors and Data', IDS Working Paper Series, No. 133, Sussex: Institute of Development Studies

Moser, C. (2003) "Apt Illustration" or “Anecdotal Information"? Can Qualitative Data be Representative or Robust?' in Ravi K. (ed.) Q-Squared: Qualitative and Quantitative Methods of Poverty Appraisal. Permanent Black.

O’Neil, M. (2005) 'What determines the influence that research has on policy-making?', Journal of International Development, 17(6):761-64

Platt, L. (2003) 'Putting Childhood Poverty on the Agenda: The Relationship Between Research and Policy in Britain 1800-1950', Young Lives Working Paper Series, No. 7, London: Young Lives

Tarrow, S. (1994) Power in Movement: Social Movements, Collective Action and Politics, New York: Cambridge University Press.

UNICEF (2005) The State Of The World's Children 2006: Excluded and Invisible, UNICEF, New York, 2005. 
Weiss, C. (1980). "Knowledge Creep and Decision Accretion" in Science Communication, 1:381-404.

White, H. (2002) 'Combining Quantitative and Qualitative Approaches in Poverty Analysis', in World Development. 30(3):511-522.

\section{Notes}

(1) Young Lives is a fifteen-year longitudinal study of childhood poverty in Ethiopia, India (Andhra Pradesh State), Peru and Vietnam (see www.younglives.org.uk). In Ethiopia, the project gratefully acknowledges financial support from DFID and IDRC, Canada. Rachel Marcus, John Wyeth and Andrew Summers provided helpful comments. All errors and opinions expressed are those of the authors.

(2) These countries were chosen based on their economic and geographical diversity. See http://younglives.qeh.ox.ac.uk/pdf/wp22.pdf

(3) For example, if the legislature is weak then linking with congressional committees is unlikely to be an effective entry point.

(4) Epistemic communities consist of colleagues who share a similar approach on an advocacy-related issue.

(5) While there is a danger that such relationships with formal government structures could potentially limit the content and way in which we disseminate our research findings, to date we have not faced any significant constraints.

(6) YL research was the only civil society research quoted in this document.

(7) See Ethiopia: Building on Progress. A Plan for Accelerated and Sustained Development to End Poverty (PASDEP). Ministry of Finance and Economic Development. September 2006.

(8) See http://younglives.qeh.ox.ac.uk/pdf/wp22.pdf for further details. 